\title{
Bloqueio Peridural Caudal: Técnica Anestésica de Uso Exclusivo em Crianças? É Possível sua Realização em Adultos? Qual o Papel do Ultrassom nesse Contexto?
}

\author{
Ilana Esquenazi Najman ${ }^{1}$, Thiago Nouer Frederico ${ }^{2}$, Arthur Vitor Rosenti Segurado, TSA ${ }^{3}$, \\ Pedro Paulo Kimachi, TSA 4
}

\begin{abstract}
Resumo: Najman IE, Frederico TN, Segurado AVR, Kimachi PP - Bloqueio Peridural Caudal: Técnica Anestésica de uso Exclusivo em Crianças? É Possível sua Realização em Adultos? Qual o Papel do Ultrassom nesse Contexto?

Justificativa e objetivos: O bloqueio peridural caudal é a mais popular entre todas as técnicas de anestesia regional em crianças. Com o avanço da idade, apenas a relativa dificuldade em localizar o hiato sacral limita seu uso. Entretanto, em adultos a técnica vem sendo largamente utilizada para controle de dor crônica com o auxílio da fluoroscopia. Assim, a habilidade em localizar o hiato e definir as variações anatômicas é o principal fator determinante do sucesso e segurança na execução do bloqueio peridural pela via caudal. Nesse contexto, o ultrassom vem ganhando espaço como guia para a realização do bloqueio caudal. O objetivo desta revisão foi elucidar o papel do ultrassom na anestesia caudal, além de demonstrar que o bloqueio caudal, muito utilizado em crianças, também é útil e pode ser usado em adultos.
\end{abstract}

Conteúdo: Uma revisão literária sobre a anatomia da região sacral e da técnica anestésica necessária para a realização adequada do bloqueio caudal foi promovida. Além disso, artigos recentes sobre estudos realizados com bloqueios peridurais caudais guiados por ultrassom tanto em crianças quanto em adultos também foram incluídos.

Conclusões: O ultrassom, apesar de suas limitações, pode ser útil como ferramenta adjuvante no posicionamento da agulha no espaço caudal. Permite a fácil identificação da anatomia sacral, além de visualização da injeção, em tempo real. Sua natureza portátil, não invasiva e livre de exposição à radiação faz dele uma tecnologia atrativa na sala operatória, principalmente na emergência de casos difíceis. Entretanto, como seu uso em bloqueios centrais do neuroeixo ainda é muito primitivo, é necessário que mais pesquisas sejam feitas para se consagre como técnica de rotina na prática anestésica.

Unitermos: ANESTESIA, pediátrica; EQUIPAMENTOS, Ultrassom; TÉCNICAS ANESTÉSICAS, Regional: peridural sacral.

[Rev Bras Anestesiol 2011;61(1): 95-109] @Elsevier Editora Ltda.

\section{INTRODUÇÃO}

O bloqueio peridural caudal é a mais popular entre todas as técnicas de anestesia regional em crianças ${ }^{1,2}$.

A abordagem do espaço peridural pela via caudal é feita através do hiato sacral ${ }^{1}$. O sacro situa-se na extremidade distal da coluna vertebral e é composto por cinco vértebras fundidas em uma estrutura óssea única ${ }^{3}$.

O hiato sacral situa-se na parte inferior da parede posterior do sacro e se forma pela ausência de fusão dorsal dos arcos posteriores da quinta vértebra sacral. Pode ser facil-

Recebido do Hospital Sírio-Libanês, São Paulo, SP.

1. Anestesiologista do Hospital Infantil Ismélia Silveira; Hospital Municipal Jesus; Aluna do Curso de Aperfeiçoamento em Anestesia Regional do IEP - Hospital Sírio Libanês/Hospital das Clínicas da Faculdade de Medicina da Universidade de São Paulo - HCFMUSP, 2009. 2. Anestesiologista

3. Anestesiologista da São Paulo Serviços Médicos de Anestesia; Tutor do Curso de Aperfeicoamento em Anestesia Regional do IEP - Hospital Sírio Libanês/HCFMUSP

4. Anestesiologista da São Paulo Serviços Médicos de Anestesia; Coordenador do Curso de Aperfeiçoamento em Anestesia Regional do IEP - Hospital Sírio Libanês/ HCFMUSP

Submetido em 2 de maio de 2010

Aprovado para publicação em 27 de julho de 2010

Correspondência para:

Dra. Ilana Esquenazi Najman

Rua Bolívar 87/801

Copacabana

22061-020 - Rio de Janeiro, RJ

E-mail: ilanaen@gmail.com mente identificado pela palpação como uma fenda triangular, com forma de " $v$ " invertido, acima da goteira sacrococcígea. O hiato é recoberto por uma estrutura fibrosa formada pelo entrelaçamento das fibras dos ligamentos sacrococcígeo superficial e profundo. Essa estrutura, denominada simplesmente membrana sacrococcígea, oblitera a extremidade distal do espaço epidural. Assim, a habilidade em localizar o hiato e definir as variações anatômicas é, portanto, o principal fator determinante do sucesso e segurança na execução do bloqueio peridural pela via caudal. O hiato sacral abre-se diretamente sobre o canal do sacro, extremidade distal do canal espinhal ${ }^{1}$.

O canal sacral contém a cauda equina, as meninges espinhais, tecido adiposo e o plexo venoso sacral. Com o avançar da idade, os ligamentos sobrejacentes e o corno se tornam mais espessos. Em consequência, a identificação das margens do hiato se torna um desafio. Com isso, os problemas práticos relacionados à anestesia caudal são principalmente atribuídos a uma ampla variação anatômica em tamanho, formato e orientação do sacro ${ }^{3}$.

Em crianças, o bloqueio caudal geralmente é indicado para analgesia intra e pós-operatória. Procedimentos que envolvam a área de distribuição dos dermátomos T10 a S5 em menores de oito anos ou com peso inferior a $30 \mathrm{~kg}$ são os mais adequados. Acima dessa faixa etária, apenas a relativa 
dificuldade em localizar o hiato sacral limita o uso da anestesia peridural caudal ${ }^{1}$.

Em adultos, a técnica é usada principalmente para controle de dor crônica ${ }^{3}$. Adultos são colocados na posição prona para o bloqueio, enquanto crianças são posicionadas em decúbito lateral ${ }^{3}$.

Avanços recentes em ultrassonografia melhoraram significativamente o entendimento da sonoanatomia espinhal. Com isso, atualmente, a imagem do ultrassom tem sido usada para determinar ou guiar bloqueios neuraxiais centrais. Isso ocorre porque o ultrassom é uma ferramenta não invasiva, segura e simples de ser usada. Pode ser rapidamente utilizada, não envolve exposição à radiação, além de promover imagens em tempo real e estar livre de efeitos adversos. Assim, um escaneamento pré-punção permite ao operador prever a anatomia espinhal, identificar a linha média, predizer com precisão a profundidade do espaço peridural, além de determinar o sítio ótimo para a realização da punção e a trajetória para inserção da agulha. Além disso, quando usado em bloqueios centrais de neuroeixo, também melhora a taxa de sucesso do acesso peridural na primeira tentativa, diminui o número de tentativas de punções ou a necessidade de múltiplas punções e melhora o conforto do paciente durante o procedimento ${ }^{4}$.

Pesquisas preliminares sugerem que o ultrassom também oferece vantagens técnicas em pacientes com anatomia espinhal anormal ${ }^{4}$.

O objetivo desta revisão foi elucidar o papel do ultrassom na anestesia peridural caudal, além de demonstrar que a técnica - muito utilizada em crianças - também é útil e pode ser usada em adultos. Também se descreveu uma revisão da anatomia e da técnica anestésica do bloqueio caudal com e sem o auxílio do ultrassom, tanto em adultos quanto em crianças.

\section{CONTEÚDO}

\section{Técnica de bloqueio peridural caudal simples em crianças}

A técnica de anestesia regional mais popular em crianças é o bloqueio peridural caudal, que é relativamente fácil de ser realizado desde que as marcações corretas tenham sido identificadas. Normalmente realizado sob anestesia geral, as marcações importantes são o cóccix e o hiato sacral localizado entre os dois cornos sacrais ${ }^{2}$.

O bloqueio peridural caudal simples tem sido amplamente praticado utilizando-se uma grande variedade de agulhas hipodérmicas, intravenosas, agulhas para raquianestesia e para punção peridural. A maioria dos autores desaconseIha a utilização desse material inespecífico para a prática de abordagem peridural pela via sacral ${ }^{1}$. Desse modo, a agulha ideal deve ter mandril obturador, bisel curto e calibre variando entre 20 e 23 gauge. Além disso, é importante lembrar a possibilidade de formação de cisto dermoide pelo avanço de tecidos dérmicos ou subdérmicos para o espaço peridural.
Assim, caso sejam utilizadas agulhas sem mandril obturador, é importante efetuar um pertuito cutâneo com outra agulha antes da punção, com o intuito de prevenir a transposição tecidual ${ }^{1,3}$.

Para a realização do bloqueio caudal, a criança deve ser previamente monitorada com oxímetro de pulso, cardioscópio, pressão arterial não invasiva e ter acesso venoso estabelecido. A criança, então, é posicionada em decúbito lateral, preferencialmente esquerdo, com as pernas fletidas a $90^{\circ}$ sobre o quadril e $45^{\circ}$ sobre os joelhos. O posicionamento da cabeça deve atender à preservação das vias aéreas livres. $O$ hiato sacral pode ser identificado como vértice inferior de um triângulo equilátero projetado a partir das espinhas ilíacas póstero-superiores ${ }^{1}$.

A antissepsia da pele deve ser cuidadosa, em virtude da proximidade com o orifício anal ${ }^{1}$. A agulha é então inserida 1-2 mm caudal do ponto médio entre os dois cornos, na porção proximal do vértice do hiato, com um ângulo de aproximadamente $45^{\circ}$ em relação à pele. Após sentir-se a perda de resistência ou o "clique" característico da passagem pela membrana sacrococcígea, reorienta-se a agulha, diminuindo o ângulo para $20-30^{\circ}$ e, em seguida, avança-se de 2-3 mm no interior do canal do sacro ${ }^{1,2}$.

Uma vez dentro do espaço peridural, devem-se tomar alguns cuidados para evitar o avanço da agulha, já que o saco dural em crianças pequenas pode estender-se ao nível de S3-S4 (em oposição à S2 em adultos) e pode ocorrer punção dural não intencional ${ }^{2}$. Assim, o posicionamento intravascular ou subaracnoideo deve ser descartado mediante aspiração suave com seringa ou mantendo-se a agulha aberta para o ambiente 10-15 segundos. Lembrar que a aspiração negativa para sangue e/ou líquor não é confiável, pela alta complacência das veias epidurais e do espaço intratecal em crianças, que colapsa facilmente ${ }^{1}$.

Procede-se, então, à injeção da dose teste e, após 3060 segundos, a solução anestésica é injetada lentamente, com aspirações frequentes e observação dos parâmetros da monitoração ${ }^{1}$. É importante ressaltar que a dose-teste $(0,1$ $\mathrm{mL}$.kg de solução anestésica local contendo adrenalina 1 : 200.000) deve ser realizada a despeito de sua controversa eficácia em crianças. Aumento na amplitude da onda $T$ superior a $25 \%$ da linha de base ou aumento da frequência cardíaca maior que 10 bpm são indicativos de injeção intravascular de adrenalina. Pode ocorrer aumento da pressão sanguínea sistólica em $15 \mathrm{mmhg}$. Porém, esse parâmetro é menos confiável do que alterações na onda $T$ e na frequência cardíaca ${ }^{2}$.

A perfuração da dura-máter é pouco frequente quando a técnica é executada corretamente. Não há relatos na literatura de complicações infecciosas, como formação de abscesso ou meningite, após anestesia peridural por dose única. Sua ocorrência está mais relacionada à permanência de cateter para analgesia pós-operatória ${ }^{3}$.

Em geral, complicações como injúria neurológica, hematoma peridural, infecção e punção dural são raras ou incomuns quando a técnica para a realização do bloqueio é utilizada de forma apropriada ${ }^{3}$. 


\section{Técnica de bloqueio peridural caudal simples em adultos}

Em adultos, a posição prona é a mais usada para a realização do bloqueio peridural caudal, diferentemente das crianças em que o bloqueio caudal deve ser realizado com o paciente completamente anestesiado e em decúbito lateral pelo fácil acesso à via aérea. Assim, na posição prona, um coxim deve ser usado abaixo da sínfise púbica e da crista ilíaca para produzir uma leve flexão dos quadris. Essa manobra facilita a palpação do canal caudal ${ }^{3}$.

A preparação estéril da pele deve, então, ser realizada e, após a identificação do hiato sacral, procede-se à infiltração local subcutânea com lidocaína a $1 \%{ }^{3}$.

Se for utilizada fluoroscopia, o canal sacral aparece como camada posterior translucente aos segmentos sacrais. A crista sacral mediana é visualizada como uma linha posterior opaca ao canal caudal. O hiato sacral é geralmente visualizado como uma abertura translucente na base do canal caudal. E o cóccix deve ser visto articulando-se com a superfície inferior do sacro ${ }^{3}$.

No adulto, a agulha ideal para a realização do procedimento deve ser do tipo Touhy 17 ou 18G. A agulha é então inserida na linha média do canal caudal, e um leve "estalo" deve ser apreciado à medida que a agulha for avançando pelo ligamento sacrococcígeo. Uma vez que a agulha alcance a parede ventral do canal sacral, deve ser vagarosamente retraída e reorientada, em sentido mais cranial, para sua posterior inserção no canal. A técnica de perda de resistência deve ser utilizada para confirmação da entrada da agulha no espaço peridural. É importante lembrar que sua ponta deve estar abaixo de S2, que corresponde à marcação na pele 1 cm inferior à espinha ilíaca póstero-superior, a fim de se evitar a perfuração da dura ${ }^{3}$.

Deve-se descartar o posicionamento subcutâneo, intravascular ou subaracnoideo da agulha. E, se sua ponta estiver no periósteo, haverá certa resistência à injeção, levando o paciente a apresentar uma sensação extremamente desagradável ${ }^{3}$. Desse modo, na prática clinica há várias maneiras de se identificar o espaço peridural caudal. O mais comum é a presença do "estalo" característico na penetração do ligamento sacrococcígeo, apesar de a perda da resistência ser o mais confiável. Já a confirmação do posicionamento correto da agulha pode ser feita por meio da observação da falta de intumescimento subcutâneo ou resistência à injeção, da estimulação elétrica nervosa com contração do esfíncter anal como resposta e da determinação dos efeitos clínicos do fármaco injetado 4,5 .

Complicações graves não ocorrem com frequência, mas incluem abscesso peridural, meningite, hematoma peridural, punção dural e cefaleia pós-punção, injeção subdural, pneumoencéfalo e embolismo aéreo, dor lombar e ruptura de cateter ${ }^{3}$.

\section{Técnica de bloqueio peridural caudal guiada por ultrassom}

A imagem ultrassonográfica do sacro deve ser realizada a fim de se identificar a sonoanatomia relevante para a injeção peridural caudal. É importante lembrar que, como o sacro é uma estrutura superficial, um transdutor linear de alta frequência deve ser usado para escaneá-lo ${ }^{4}$.

Num sonograma transverso do sacro, no nível do hiato sacral, as duas proeminências ósseas do corno sacral são vistas como duas estruturas hiperecoicas em formato de $U$ invertido, em cada lado da linha média. Conectando os dois cornos sacrais, existe uma banda hiperecoica, que é o ligamento sacrococcígeo. Anteriormente ao ligamento sacrococcígeo, existe outra estrutura linear hiperecoica, que representa a superfície posterior do sacro. O espaço hipoecoico entre o ligamento sacrococcígeo e a superfície óssea posterior do sacro é o hiato sacral ${ }^{4,6}$ (Figura 1).

Já num sonograma sagital do sacro, no nível do corno sacral, o ligamento sacrococcígeo, a base do sacro e o hiato sacral também podem ser claramente visualizados. Desse modo, acima do hiato sacral no sonograma sagital, o sacro é identificado como uma banda hiperecoica lisa, com uma larga sombra acústica anterior a ele. E, se o transdutor for desliza-

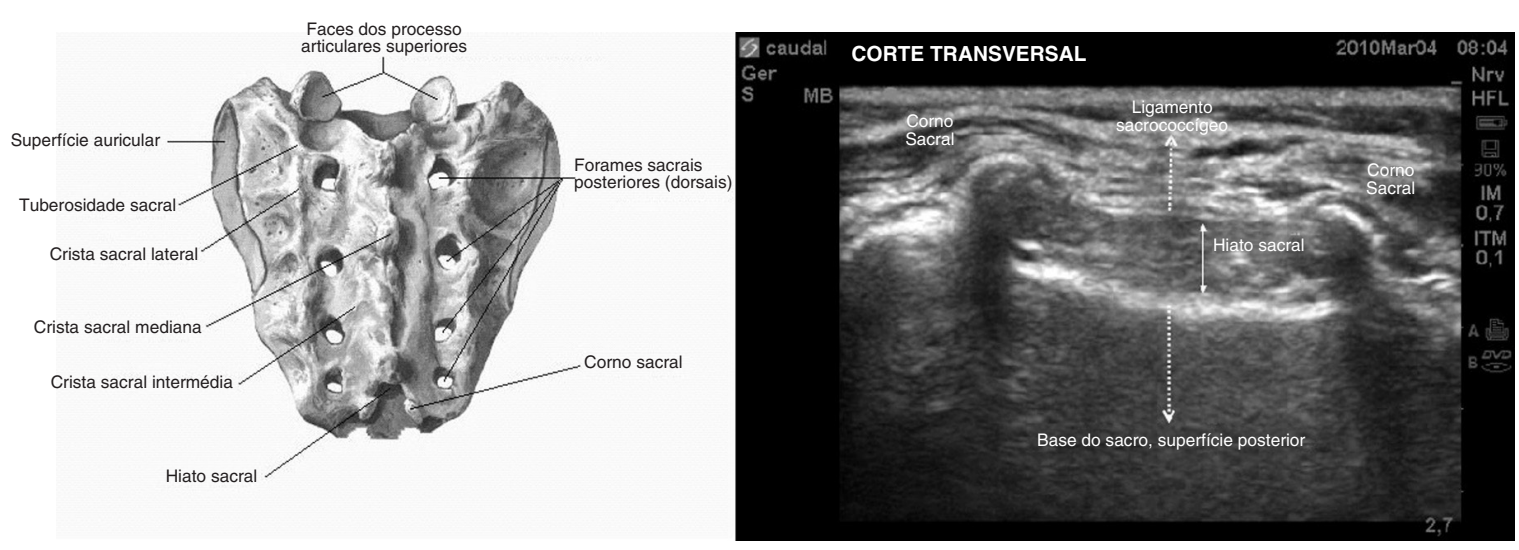

Figura 1 - Ilustração Anatômica do Sacro e Imagem Ultrassonográfica da Região Sacral em Corte Transversal, com Identificação das Estruturas Relevantes para Realização do Bloqueio Peridural Caudal. 
do cefalicamente, mantendo-se a mesma direção, o espaço visto entre o sacro e a lâmina de L5 (escaneamento paramendiano sagital) é o espaço intervertebral L5/S1. Tal marcação sonográfica tem sido comumente usada para identificar um espaço intervertebral lombar específico, por sua continuidade para cima ${ }^{4}$ (Figura 2 ).

Sabe-se que o ultrassom é mais preciso do que a palpação para se identificar um dado espaço intervertebral lombar. No entanto, como a localização ultrassonográfica do espaço intervertebral lombar recai sobre a habilidade individual em localizar o espaço L5/S1 no sonograma, existem limitações desse método na presença de L5 sacralizada ou S1 lombarizada, quando o interespaço L4/L5 pode ser subinterpretado como L5/S1. Assim, como não é possível prever a situação citada sem o auxílio de imagem alternativa (radiografia, tomografia computadorizada ou ressonância magnética), o espaço

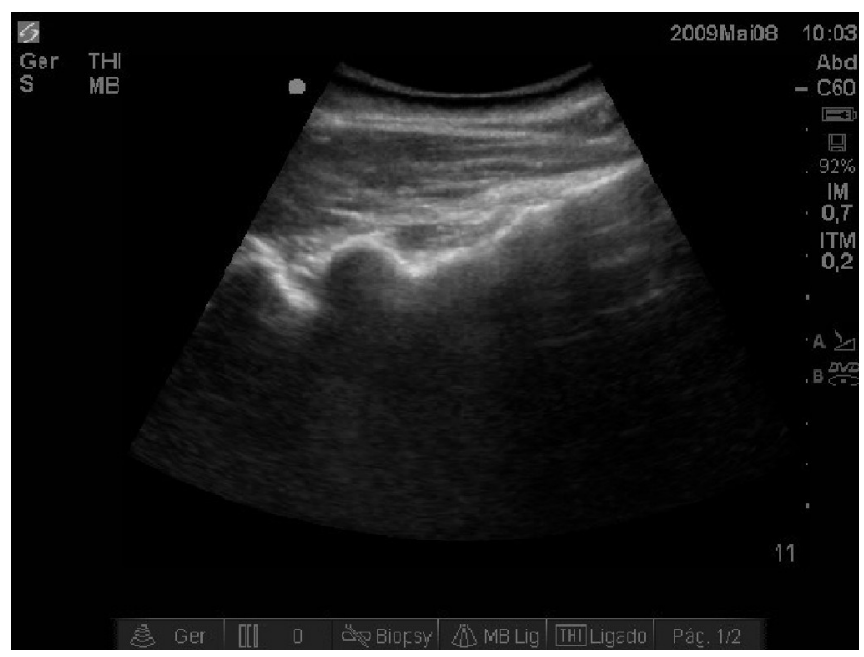

Figura 2 - Imagem Ultrassonográfica em Corte Longitudinal da Coluna Vertebral. Identificação das Facetas de L4, L5 e do Sacro (linha hiperecoica contínua).
L5/S1 ainda é uma marcação útil quando usada para ultrassonografia. Porém, deve-se ter em mente que, vez ou outra, o nível de identificação intervertebral pode estar distante 1 a 2 níveis intervertebrais ${ }^{4}$.

Para injeção peridural caudal, um escaneamento transverso sagital é realizado no nível do hiato sacral, usando-se um transdutor linear de alta frequência (6-13 MHz), como já descrito. A agulha do bloqueio pode ser inserida em plano ou fora de plano. Para inserção em plano, o escaneamento sagital é realizado e a passagem da agulha através do ligamento sacrococcígeo no canal sacral é visualizada em tempo real. No entanto, como o sacro impede a passagem do feixe de ultrassom, há uma larga sombra acústica anteriormente que torna impossível a visualização da ponta da agulha ou da dispersão da injeção dentro do canal sacral ${ }^{4}$.

A técnica de punção peridural caudal guiada por ultrassom também é descrita com a utilização longitudinal do transdutor (Figuras 3 e 4). Desse modo, após inserção da agulha entre os dois cornos até o hiato sacro e percepção do "click" característico com a penetração do ligamento sacrococcígeo, o transdutor é rodado $90^{\circ}$ para obtenção da visão longitudinal do sacro e hiato sacral. A agulha é, então, avançada até o canal sacral sob visualização direta em tempo real longitudinalmente. No entanto, em adultos costuma ser difícil seguir a agulha se ela se encontrar no hiato sacral. Isso ocorre devido à presença de artefatos ósseos da parede do sacro. Portanto, após aspiração negativa para sangue e ou líquor, a injeção deve ser feita com o ultrassom para que se possa notar a turbulência no canal sacral e a dispersão cefálica da solução injetada no monitor, o que, mesmo assim, continua não sendo uma tarefa fácil em adultos ${ }^{6}$ (Figura 5).

É importante lembrar que a injeção intravascular inadvertida é reportada em $5 \%$ a $9 \%$ nesses procedimentos e não pode ser detectada com o uso do ultrassom ${ }^{4}$. Desse modo, Doppler pode ser usado apesar de não ser confiável, já que a turbulência da injeção pode ser interpretada como fluxo em muitas direções com diferentes cores, sendo erroneamente avaliadas como injeção intravenosa. Com isso, o autor relata
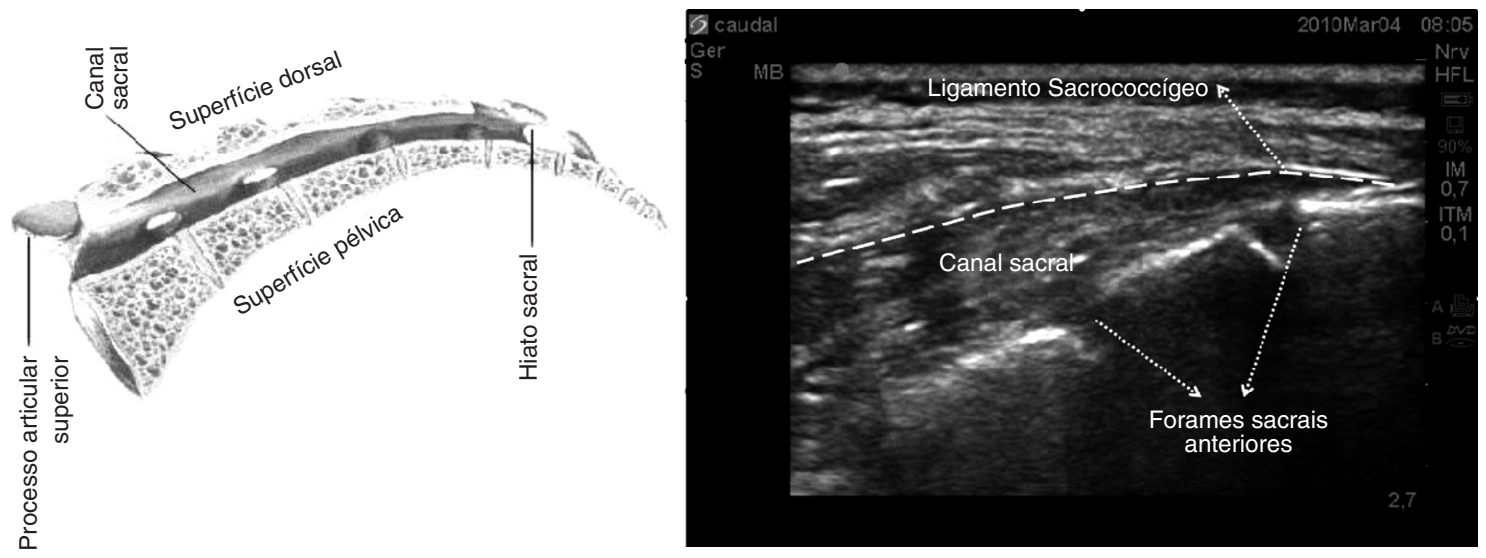

Figura 3 - Ilustração Anatômica do Canal Sacral e Visualização de sua Imagem Ultrassonográfica em corte Longitudinal. 


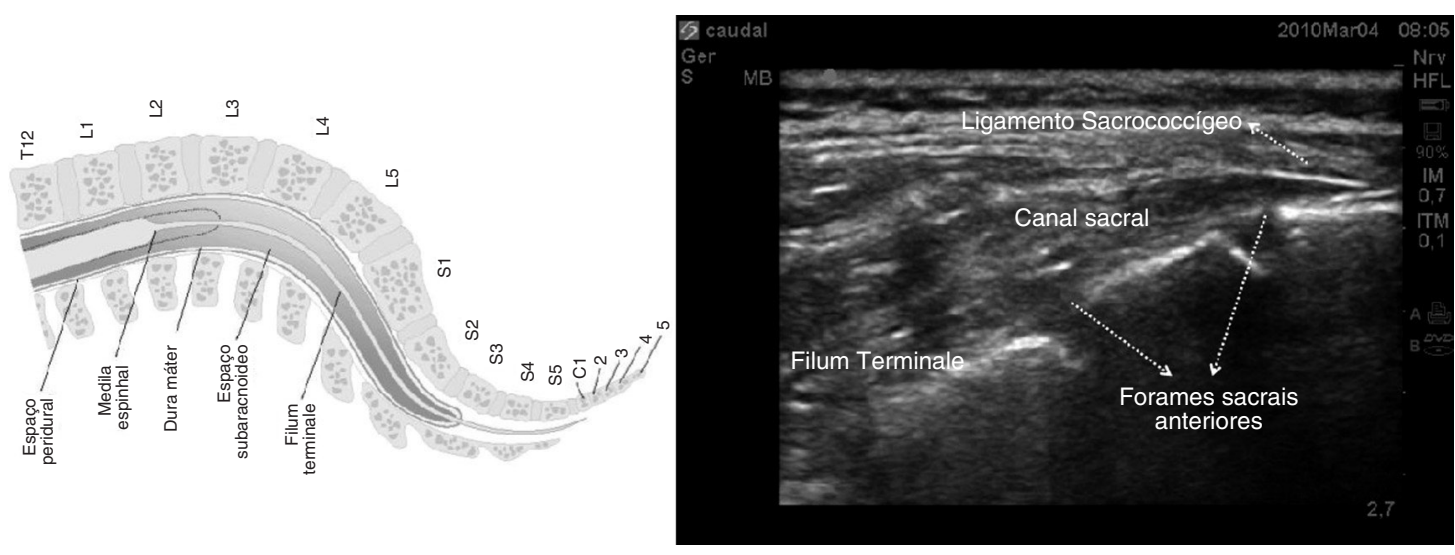

Figura 4 - Comparação Anatômica das Estruturas da Região Lombossacral com a Imagem Ultrassonográfica Caudal Obtida em Corte Longitudinal.

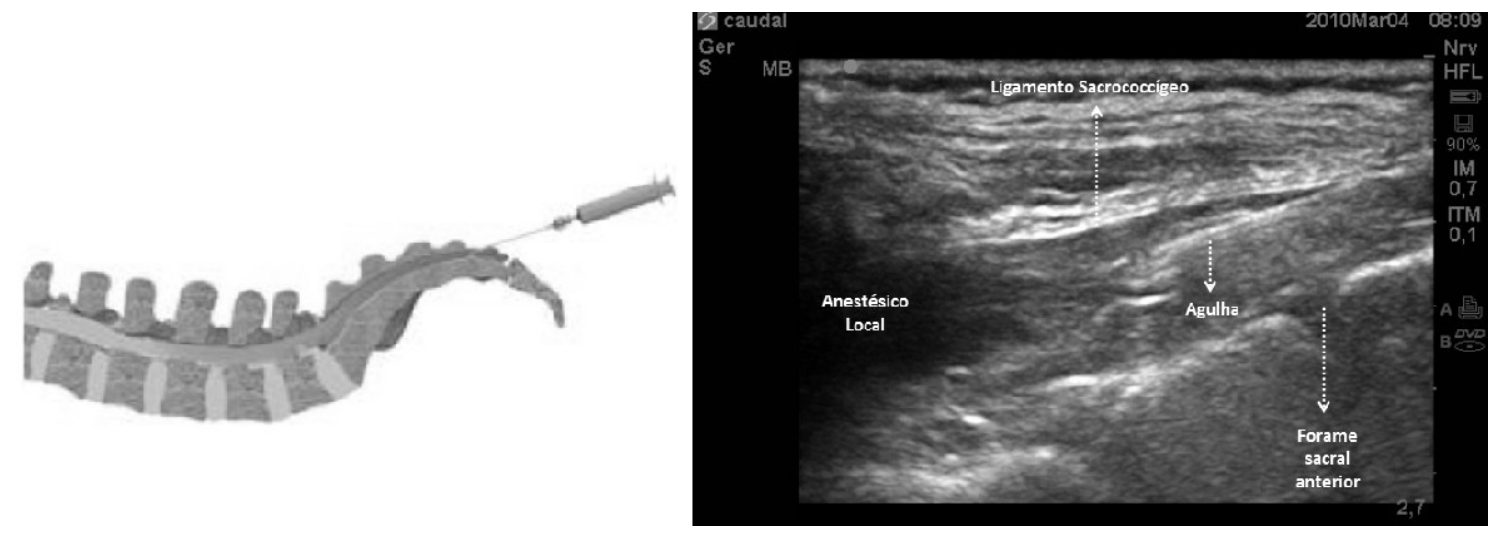

Figura 5 - Ilustração Anatômica Indicando o Ponto de Introdução da Agulha para a Realização do Bloqueio Peridural Caudal. Imagem Ultrassonográfica em Corte Longitudinal do Canal Sacral, com Visualização da Agulha em seu Interior. Turbilhonamento Cefálico do Anestésico Local após sua Injeção no Espaço Peridural Caudal, em Criança de 28 dias de Vida.

que a melhor forma de descartar a injeção intravenosa ou intratecal é ainda por fluoroscopia. Consequentemente, o ultrassom pode ser usado caso a fluoroscopia não esteja disponível ou como guia para a colocação da agulha no canal sacral como adjuvante à fluoroscopia ${ }^{6}$.

Em crianças, o bloqueio peridural caudal guiado por ultrassom é realizado após indução de anestesia geral e posicionamento em decúbito lateral. Coloca-se uma marcação onde se imagina que a punção caudal deva ser realizada. Em seguida, o anestesiologista realiza o exame ultrassonográfico, primeiro no plano transverso, começando da ponta do cóccix em direção ao sacro, com a finalidade de mostrar a marcação realizada previamente ao ultrassom. Isso é então repetido usando-se o probe longitudinal e o paciente é submetido a uma palpação estéril ${ }^{7}$.

A agulha é inserida (21G regional ou 20G cateter vascular) e o probe do ultrassom é posicionado (após estar estéril) cefalicamente ao sítio de injeção no plano transverso, aproximadamente na ponta da agulha. Enquanto um assistente ausculta alterações na frequência cardíaca e observa a morfologia eletrocardiográfica, a solução caudal é injetada em pequenas porções. Dilatação do espaço caudal e turbulências localizadas são notadas na tela do ultrassom, confirmando a colocação bem-sucedida da agulha no espaço peridural caudal. O modo colorido para indicar fluxo de fluido no espaço caudal também é utilizado ${ }^{7}$.

É importante ressaltar que a turbulência durante a injeção pode ser mais bem visualizada quando a profundidade do ultrassom é ajustada para $2 \mathrm{~cm}$. Além disso, exames ultrassonográficos repetidos têm permitido o reconhecimento relevante da anatomia sacrococcígea em crianças ${ }^{7}$.

\section{Revisão da literatura sobre bloqueio peridural caudal guiado por ultrassom}

Chen e col. ${ }^{5}$ conduziram um estudo entre agosto de 2002 e juIho de 2003, com 70 pacientes que apresentavam neurite lom- 
bossacral. Utilizaram transdutor de alta frequência (5-12 MHz) para a identificação do hiato sacral. Inicialmente, uma imagem ultrassonográfica transversa do hiato sacral foi obtida para se identificarem as marcações apropriadas. Em seguida, através de visão longitudinal, a agulha 21G Tuohy era avançada sob visão direta para o espaço peridural caudal. A colocação apropriada da agulha foi confirmada por fluoroscopia. O avanço da agulha peridural caudal ao hiato sacro e ao espaço peridural caudal foi observado através de imagens ultrassonográficas em tempo real e contínuo. Houve $100 \%$ de sucesso na colocação da agulha no espaço peridural caudal. No entanto, observaram que a ponta da agulha não pôde ser visualizada após sua inserção no espaço peridural sacral pelo ultrassom devido a artefatos ósseos. Aspiração foi o único método utilizado para a identificação da presença de líquor ou sangue ${ }^{5,6}$.

Gross ${ }^{8}$ critica o estudo citado, relatando que Chen e col. demonstraram uma taxa de $100 \%$ de sucesso na identificação correta do espaço peridural caudal, na ausência de um grupo controle. Isso, apesar de terem citado uma pesquisa com $25 \%$ de taxa de falência quando o bloqueio caudal foi realizado por perda de resistência. Assim, embora a técnica pareça ser promissora, o autor sugere que se faça uma comparação individual com a técnica de perda de resistência. $\mathrm{E}$ que, além disso, é necessária uma padronização pela igualdade técnica dos operadores, para que se estabeleça a superioridade da técnica guiada por ultrassom.

A ausência de métodos alternativos à aspiração para detecção de sangue e ou líquor no estudo de Chen ${ }^{5}$ levou Yoon e col. a avaliar o uso do Doppler ultrassonográfico na injeção caudal, com o intuito de identificar qualquer injeção intravenosa. Assim, após acesso do espaço peridural, eram injetados $5 \mathrm{~mL}$ da solução enquanto observava-se o fluxo com o uso do transdutor de alta resolução (5-12 MHz) e o modo colorido do Doppler. A injeção era então definida como bem-sucedida se o fluxo unidirecional (cor dominante) da solução fosse observado com o Doppler ultrassonográfico através do espaço peridural abaixo do ligamento sacrococcígeo. Nenhum fluxo podia ser observado em outras direções (múltiplas cores). O posicionamento correto da medicação foi então confirmado por contraste fluoroscópico. Com isso, em 52 dos 53 pacientes avaliados, a medicação foi injetada de forma bem-sucedida no espaço peridural caudal com a ajuda do ultrassom. Na fluoroscopia desses 52 pacientes, 50 revelaram posicionamento correto da medicação no espaço peridural caudal. No entanto, três pacientes, incluindo um com Doppler negativo e dois com Doppler positivo, mostraram contraste saindo do espaço peridural ${ }^{6}$.

Em outro estudo, Klocke e col. descreveram o uso da injeção peridural caudal de corticoesteroides guiada por ultrassom. Eles acharam isso particularmente útil em pacientes moderadamente obesos ou em pacientes com dificuldade de posicionamento em decúbito ventral. Reportaram boa visualização das marcações, mas necessitaram de transdutor de baixa frequência $(2-5 \mathrm{MHz})$ em pacientes obesos para atingir a penetração adequada ${ }^{6}$.

Recentemente, conduziu-se um estudo observacional retrospectivo sobre injeção caudal em 83 pacientes pediátricos. O objetivo do estudo foi a comparação da precisão do posicionamento peridural caudal da agulha entre dois testes confirmatórios, o teste swoosh (ausculta com estetoscópio na região sacral durante injeção caudal de anestésico local) e a imagem ultrassonográfica em tempo real (ultrassom bidimensional transverso e fluxo colorido no Doppler). Os autores concluíram que o ultrassom é superior ao teste swoosh, como técnica confirmatória objetiva durante o bloqueio caudal em crianças. Desse modo, relatam que a presença ou ausência da turbulência à imagem ultrassonográfica durante a injeção de anestésico local dentro do espaço caudal seria o melhor indicador de sucesso do bloqueio ${ }^{6,9}$.

No entanto, a falta de pesquisas sobre a taxa de sucesso do posicionamento adequado da agulha peridural caudal em crianças levou à realização de um estudo comparativo entre a precisão da colocação da agulha durante a prática rotineira e a graduação da visão ultrassonográfica disponível em relação à eficácia final do bloqueio. Nesse contexto, foram estudados 53 bloqueios caudais guiados por ultrassom em crianças na faixa etária de 1-72 meses submetidas à cirurgia abdominal baixa. A agulha foi diretamente visualizada no espaço peridural caudal em 45 dos 53 bloqueios. Dos 45 bloqueios em que a agulha pôde ser vista, a injeção foi claramente visualizada no espaço peridural caudal. Tais bloqueios foram considerados bem-sucedidos segundo sinais vitais intraoperatórios e critérios pós-operatórios adotados pela enfermagem. Em cinco pacientes, a agulha não pôde ser visualizada no ultrassom, mas a injeção foi vista dentro do espaço peridural caudal. Tais bloqueios foram considerados bem-sucedidos segundo os critérios citados. Nos três pacientes em que nem a agulha nem a injeção puderam ser visualizadas, o bloqueio foi considerado falho tanto pelos sinais vitais intraoperatórios quanto por critérios pós-operatórios determinados pela enfermagem. Desse modo, segundo o estudo, achados ultrassonográficos estão associados à previsão correta do sucesso ou insucesso do bloqueio $(p<0,001)^{10}$.

Schwartz e col. ${ }^{11}$ relatam um caso de dificuldade técnica de realização de bloqueio caudal em criança de 8 meses, submetida a herniorrafia inguinal e postectomia. De acordo com o relato, o sucesso foi possibilitado com o auxílio do ultrassom. O bloqueio caudal nessa criança foi inicialmente impossibilitado pelo intumescimento subcutâneo da região sacral por posicionamento inadequado da agulha, dificultando, assim, a identificação anatômica necessária para o bloqueio. Consequentemente, realizou-se uma visão ultrassonográfica transversa do sacro (transdutor linear perpendicular ao eixo espinhal). Isso possibilitou a rápida identificação do corno e hiato sacral, além de marcação da agulha na pele sobre o ligamento sacrococcígeo no meio dos cornos. Em seguida, alguns centímetros acima do ponto de injeção, uma nova imagem no plano transverso foi realizada e a turbulência característica pôde ser vista no espaço caudal. O fluxo também foi detectado com o modo Doppler. Dessa forma, a ausência de alterações dos sinais vitais durante a cirurgia, a presença de um bloqueio motor parcial nas extremidades inferiores à emergência da anestesia e uma estada confortável na unidade de recuperação pós-anestésica levaram a classificação do bloqueio como bem-sucedido. 


\section{DISCUSSÃO}

A anestesia peridural caudal é a injeção de medicamentos no espaço peridural via hiato sacral. É útil quando a anestesia de dermátomos lombares e sacrais é necessária.

O bloqueio peridural caudal é a mais popular dentre todas as técnicas de anestesia regional em crianças de até 8 anos de idade. Acima dessa faixa etária, apenas a relativa dificuldade em localizar o hiato sacral limita seu uso. Entretanto, em adultos, a técnica tem sido largamente utilizada principalmente para controle de dor crônica. Desse modo, a anestesia caudal bem-sucedida requer o posicionamento adequado da agulha no espaço peridural.

Apesar disso, a taxa de falência do posicionamento da agulha no espaço peridural caudal pode ser maior que $25 \%$, mesmo em mãos experientes ${ }^{5}$. Nesse contexto, o ultrassom vem ganhando espaço como guia para a realização do bloqueio peridural caudal. Isso ocorre porque o ultrassom permite a fácil identificação da anatomia sacral, além de visualização da injeção no espaço caudal durante o bloqueio. Sua natureza portátil e não invasiva faz dele uma tecnologia atrativa na sala cirúrgica, principalmente na emergência de casos difíceis. Com isso, ultimamente, muitos grupos têm descrito o uso do ultrassom durante bloqueios caudais tanto em crianças quanto em adultos ${ }^{11}$.

Como sabemos, o sacro e o cóccix são formados pela fusão de oito vértebras (cinco sacrais e três coccígeas). Como resultado, há um defeito natural presente pela fusão incompleta da porção inferior de S4 e S5 na linha média posterior. Esse defeito é chamado de hiato sacral e é coberto pelo ligamento sacrococcígeo. O hiato é limitado lateralmente pelo corno sacral e sua base é compreendida pelo aspecto posterior do sacro. Porém, é importante lembrar que variações anatômicas do sacro e da neurovasculatura dentro do canal sacral estão presentes em mais de $10 \%$ dos casos. Isso representa um desafio durante a injeção de medicamentos no espaço peridural caudal. Assim, a literatura relata a presença de injeção intravascular inadvertida em torno de 2,5\% a $9 \%$ em que a aspiração negativa para sangue não se mostrou nem sensível nem específica para o posicionamento da agulha ${ }^{6}$.

Além disso, a injeção intravascular é mais comum em pacientes mais velhos, já que o plexo venoso epidural que, em geral, acaba em S4 pode continuar inferiormente nesses pacientes. Assim, mais uma vez a literatura ressalta a importância da realização da injeção peridural caudal com estudos de imagem em tempo real, com o intuito de maximizar os resultados e minimizar as complicações ${ }^{6}$.

Em adultos, as injeções peridurais de anestésicos locais e corticoesteroides têm sido largamente utilizadas para promover alívio sintomático em pacientes com desordens lombares baixas na clínica de dor. Tais injeções podem ser feitas por via translaminar, transforaminal e caudal. No entanto, a via caudal como acesso para o espaço peridural tem sido preferida por muitos praticantes, já que a punção acidental do saco dural e subsequente risco de injeção intratecal da medicação é raro. Com esse propósito, a fluoroscopia tem sido frequentemente usada na confirmação da localização da agulha peridural caudal. Porém, a exposição radioativa se tornou a maior preocupação quando se obtêm imagens fluoroscópicas. Com isso, atualmente, imagens pulsáteis são preferidas durante a fluoroscopia porque isso diminui o tempo total de exposição em $20 \%$ a $75 \%$. Nesse sentido, o ultrassom torna-se vantajoso na localização do hiato sacral e como guia da agulha no espaço peridural caudal, já que seu uso fácil, livre de radiação, pode promover imagens contínuas e em tempo real da agulha guiada, sem exposição radioativa, tanto em condições clínicas quanto em situações virtuais. A grande desvantagem é a impossibilidade de visualização da imagem à medida que a inserção da agulha vai se tornando mais profunda, já que as ondas do ultrassom não podem penetrar no osso sacro. Desse modo, é imprescindível checar a presença de líquor antes da injeção do corticoide ${ }^{5}$.

É importante lembrar que, independentemente da técnica usada, o ultrassom em tempo real é, de longe, a intervenção mais exigente, já que é necessário um alto grau de destreza manual, coordenação entre olho e mão e habilidade para contextualizar as informações bidimensionais em uma imagem tridimensional. Assim, antes da realização da intervenção neuraxial central com o ultrassom, é preciso ter as habilidades necessárias e familiaridade com a técnica ultrassonográfica espinhal e a sonoanatomia da coluna. Além disso, deve-se considerar como o paciente será posicionado durante a intervenção com o ultrassom. Acredita-se que o paciente deva ser posicionado de forma que a máxima destreza manual seja possibilitada. Consequentemente, o operador poderá usar a mão dominante para realizar a intervenção e a mão não dominante para segurar o transdutor e realizar a visualização da imagem. Outro ponto importante é que se deve dar atenção especial para o gel utilizado sob o transdutor, que é usado para acoplar a acústica durante a visualização da imagem ultrassonográfica. Apesar de seu uso ser liberado, nenhuma pesquisa demonstra a segurança do gel nas meninges ou em estruturas neuraxiais centrais. Com isso, solução de cloreto de sódio a $0,9 \%$, aplicada através de esfregaços ou gazes estéreis, pode ser usada como agente de acoplamento alternativo, com a justificativa de manter a área sob o transdutor hidratada. Dessa forma, durante a preparação do transdutor, uma fina camada de gel estéril para ultrassom deve ser colocada sobre o mesmo, o qual então será coberto com capa plástica estéril transparente, assegurando-se que não haja ar entre a capa e o transdutor. Em seguida, a solução de cloreto de sódio a $0,9 \%$ poderá ser utilizada no transdutor já encapado ou sobre a pele. Porém, é importante lembrar que haverá uma discreta deterioração na qualidade da imagem quando comparada com aquela do escaneamento em que o gel foi utilizado, podendo ser ajustada através de ganhos de imagem. Assepsia estrita deve ser mantida durante qualquer uso de ultrassom ${ }^{4}$.

Em crianças, o bloqueio peridural caudal é feito sob anestesia geral. Assim, na prática anestésica pediátrica, o ultrassom tem provado ser uma ferramenta inestimável. Isso porque permite a rápida visualização da área sacral e familiarização com a anatomia necessária antes da realização do bloqueio. Igualmente importante é o potencial do ultrassom em confirmar o bloqueio, já que um bloqueio mal sucedido pode estar associado a uma morbidade significante particularmente em crianças pequenas, além do desconforto para o paciente. Além disso, o 
ultrassom promove inspeção direta em tempo real do espaço caudal, permitindo a visualização da injeção à medida que a mesma vai sendo administrada ${ }^{11}$. Consequentemente, a grande vantagem do ultrassom como guia em pediatria é a possibilidade de visualização direta das estruturas necessárias ao bloqueio e a observação da proximidade da agulha a estruturas neurais adjacentes prevenindo seu dano. Assim, além da visualização das estruturas intratecais, saco dural, espaço peridural e cauda equina, a visualização direta da injeção de anestésico local também pode ser contemplada em tempo real ${ }^{12}$.

Embora a imagem do ultrassom possa ser dificultada pela ossificação da coluna vertebral, em crianças prematuras é possível visualizar todas as estruturas neurais pela ossificação incompleta da coluna vertebral. Consequentemente, apesar da dificuldade, o ultrassom pode ser usado para visualizar a ponta da agulha no espaço peridural, assim como o avanço do cateter no espaço peridural em crianças muito pequenas ${ }^{12}$.

\section{CONCLUSÃO}

O bloqueio peridural caudal é uma técnica que promove analgesia e anestesia das raízes nervosas lombosacrais. Em crianças, é a técnica anestésica mais comumente usada. E, apesar de seu uso infrequente na rotina cirúrgica em adultos, tem sido usado na clínica de dor como auxílio da fluoroscopia.

O papel do ultrassom nesse contexto é que, ultimamente, vem sendo utilizado como ferramenta adjuvante do bloqueio caudal, já que é livre de radiação e pode promover imagens em tempo real. No entanto, como seu uso em bloqueios centrais do neuroeixo ainda é muito primitivo, é necessário que mais pesquisas sejam feitas para que seja consagrado como técnica de rotina na prática anestésica.

Assim, com base na literatura, conclui-se que o ultrassom, apesar de suas limitações, pode ser útil como ferramenta adjuvante na colocação da agulha peridural caudal tanto em adultos quanto em crianças. Em adultos, tem potencial para melhorar as consequências técnicas, além de minimizar a taxa de falência e exposição da radiação em condições de dor crônica e, assim, merece investigações futuras. Já em crianças, muitos estudos são necessários para averiguar a precisão da colocação da agulha durante a prática rotineira e graduar a visão ultrassonográfica disponível em relação à eficácia final do bloqueio. Isso se explica pelo fato de a maioria dos estudos ter detalhado dificuldade subjetiva com a visualização da agulha. Sendo que a visualização da ponta da agulha em tempo real evita danos nas estruturas neurais adjacentes, fato de suma importância, principalmente por ser um bloqueio realizado em crianças sob anestesia geral.

\section{REFERÊNCIAS / REFERENCES}

01. Auler Jr JOC, Teruya SBM, Jacob RSM et al. - Anestesia Pediátrica, São Paulo, Atheneu, 2008; 208-214.

02. Litman RS - Pediatric Anesthesia: the Requisites in Anesthesiology, $1^{\text {st }}$ Ed, Philadelphia, Elsevier Mosby, 2004;163-164.

03. Hadzic A - The New York School of Regional Anesthesia: Text- book of Regional Anesthesia and Acute Pain Management, New York, McGrawHill Medical, 2007;269-283, 727-745.

04. Karmakar MK - Ultrasound for central neuraxial blocks. Tech Reg Anesth Pain Manag, 2009;13:161-170.

05. Chen CPC, Tang SFT, Hsu TC et al. - Ultrasound guidance in caudal epidural needle placement. Anesthesiology, 2004;101:181-184.

06. Vydyanathan A, Narouze S - Ultrasound-guided caudal and sacroiliac joint injections. Tech Reg Anesth Pain Manag, 2009;13:157160.

07. Schwartz DA, Dunn SM, Connelly NR - Ultrasound and caudal blocks in children. Pediatr Anesth, 2006;16:900-901.

08. Gross JB - Ultrasound guidance in caudal epidural needle placement. Surv Anesthesiol, 2005;49:108.

09. Raghunathan K, Schwartz D, Connelly NR - Determining the accuracy of caudal needle placement in children: a comparison of the swoosh test and ultrasonography. Pediatr Anesth, 2008;18:606612.

10. Galante D - Utility of ultrasound in needle placement for caudal blocks in children. Pediatr Anesth, 2009;19:1229.

11. Schwartz D, Raghunathan K, Dunn S et al. - Ultrasonography and pediatric caudals. Anesth Analg, 2008;106:97-99.

12. Siddiqui $A$ - Caudal blockade in children. Tech Reg Anesth Pain Manag, 2007;11:203-207.

Resumen: Najman IE, Frederico TN, Segurado AVR, Kimachi PP Bloqueo Epidural Caudal: ¿Técnica anestésica de uso exclusivo en niños? ¿Se puede realizar en Adultos? ¿Cuál es el rol del ultrasonido en ese Contexto?

Justificativa y objetivos: El bloqueo epidural caudal es la más popular entre todas las técnicas de anestesia regional en niños. Cuando la edad avanza, apenas la relativa dificultad en localizar el hiato sacral limita su uso. Sin embargo, en los adultos, la técnica ha venido siendo ampliamente utilizada para el control del dolor crónico, con la ayuda de la fluoroscopía. Por lo tanto, la habilidad en poder ubicar el hiato y definir las variaciones anatómicas es el principal factor determinante del éxito y de la seguridad en la ejecución del bloqueo epidural por la vía caudal. En ese contexto, el ultrasonido ha venido ganando espacio como guía para la realización del bloqueo caudal. El objetivo de esta revisión fue elucidar el papel del ultrasonido en la anestesia caudal, además de demostrar que el bloqueo caudal, muy utilizado en niños, también es útil y puede ser usado en adultos.

Contenido: Se hizo una revisión literaria sobre la anatomía de la región sacral y de la técnica anestésica necesaria para la adecuada realización del bloqueo caudal. Además, también se incluyeron artículos recientes sobre estudios realizados con bloqueos epidurales caudales guiados por ultrasonido tanto en niños como en adultos.

Conclusiones: El ultrasonido, a pesar de sus limitaciones, puede ser útil como una herramienta coadyuvante en el posicionamiento de la aguja en el espacio caudal. Permite la fácil identificación de la anatomía sacral, además de la visualización de la inyección en tiempo real. Su naturaleza portátil, no invasiva y libre de exposición a la radiación, lo convierte en una tecnología atractiva en quirófano, principalmente en las situaciones de emergencia de casos complicados. Sin embargo, como su uso en bloqueos centrales del neuro eje todavía es muy primitivo, se hacen necesarias más investigaciones para que se consagre como una técnica de rutina en la práctica anestésica.

Descriptores: ANESTESIA, Especialidade: pediatría; EQUIPOS, Ultrasonido; TÉCNICAS ANESTÉSICAS, Regional: peridural sacral, anestesia peridural. 